\title{
Fusarium species: Mycotoxin production, and plant and murine pathogenicity
}

\author{
Yoshitsugu Sugiura \\ Department of Food Chemistry, Kobe Institute of Health \\ (4-6 Minatojima-nakamachi, Chuo-ku, Kobe 650-0046, Japan)
}

\begin{abstract}
Summary
Fusarium species are common filamentous fungi, and are distributed worldwide in crop fields. Some of the species are known to produce mycotoxins such as trichothecenes, zearalenone, and fumonisins, which are responsible for mycotoxicoses in humans and animals. Since 1980, I have been studying the chemical characteristics of selected Fusarium species, along with plant and murine pathogenicity caused by Fusarium crookwellense and Fusarium solani, respectively. In this review, I outline my experimental Fusarium studies, including some experiences during those studies.
\end{abstract}

Key words: Fusarium, Gibberella, mycotoxins, chemotype, pathogenicity

(Received: June 26, 2012)

\section{Introduction}

Fusarium species are a widespread cosmopolitan group of filamentous fungi that distribute commonly in soil in agricultural fields. Some of these species are major causal agents of several crop diseases such as 'head blight (scab)' ('Akakabi-byo in Japanese)' in wheat and barley, and 'ear rot' in maize in infected kernels ${ }^{1}$. In Japan, F. graminearum and its teleomorph Gibberella zeae are major causative agents responsible for sporadic epidemics of scab diseases in wheat, barley, and rice. The natural occurrence of Akakabi-byo disease has resulted in national production yield losses of wheat and barley grains ${ }^{2}$. According to the field study of Nishikado ${ }^{3)}$, scab diseases have been frequently documented in spring and autumn in wheat fields. Due to the moderate temperatures and high humidity in those seasons, the climate is suitable for conidia or ascospore dispersal of F. graminearum or G. zeae in crop fields. The prevailing distribution of those species results in a high incidence of scab diseases in wheat and barley fields.

Fusarium species are known to produce mycotoxins such as trichothecenes, zearalenone, and fumonisins. Cereal grains contaminated with trichothecenes are associated with outbreaks of human mycotoxicosis characterized by anorexia, nausea, vomiting, headache, abdominal pain, diarrhea, chills, and convulsions ${ }^{4}$. Trichothecenes are a major mycotoxin produced by some toxigenic Fusarium species including $F$. graminearum, F. sambucinum, F. sporotrichioides, F. equiseti, F. crookwellense (= F. cerealis), F. culmorum, $F$. poae, and F. acuminatum. Based on chemical features of the trichothecene nucleus, the trichothecenes produced by Fusarium species belong to two categories ${ }^{4}$ : type A-trichothecenes characterized by a functional group other than a keton at C-8, and type B-trichothecenes with only the carbonyl at C-8. The type A-trichothecenes are T-2 toxin (T-2) and HT-2 toxin, mainly produced by F. sporotrichioides, F. acuminatum and $F$. poae, and diacetoxyscirpenol (DAS) produced by F. poae, F. equiseti, F. sambucinum and F. sporotri- 
chioides. The type B trichothecenes are deoxynivalenol (DON), and 3-acetyl DON (3-ADON), 15-acetyl DON (15-ADON), and 3, 15-diacetyl DON produced by F. graminearum and F. culmorum, and nivalenol (NIV), and fusarenon-X (FX) or 4-acetyl NIV ( 4-ANIV), and 4, 15-diacetyl NIV produced by F. graminearum, F. crookwellense and F. poae. Natural occurrence of the trichothecenes has been observed worldwide in wheat, barley, corn, soybeans and related products ${ }^{5}$.

Among the type B trichothecenes, NIV, FX, and DON were found for the first time by Japanese mycotoxin researchers. In 1968, Tatsuno and co-workers ${ }^{6}$ reported NIV as a new toxic metabolite, which was isolated from rice cultures of Fusarium strain Fn-2B. The strain was previously called Fusarium nivale, but is now classified as F. kyushuense ${ }^{7}$. The following year, Ueno and co-workers ${ }^{8}$ found FX, a 4-acetyl derivative of NIV, in liquid cultures of the Fn-2B stain. In 1973, Yoshizawa and Morooka ${ }^{9)}$ reported DON and its acetyl derivatives from cultures of Fusarium roseum ( $=$ F. graminearum). A few months later, vomitoxin was reported as a toxic metabolite of F. graminearum by Vesonder, et al. ${ }^{10)}$ in the United States. DON and vomitoxin had exactly the same chemical structure, and the chemical name DON had priority over that of vomitoxin due to the date of publication. As a result, the isolation of NIV, FX, and DON was done by Japanese scientific researchers. Currently, these naturally occurring trichothecenes are of great concern as a worldwide problem in wheat and barley cultivated in agricultural fields.

On July 2011, a change in the nomenclature for fungi was made in the 18th International Botanical Congress held in Melbourne ${ }^{11}$. The Congress decided to use 'One fungus one name'. However, the meetings will continue to discuss which genus or species name of the anamorph-teleomorph should be used until 2018 . In this review, I use two names for one fungus based on the anamorph and teleomorph, which are described in the monograph of the genus Fusarium.

\section{Chemotypes of Gibberella zeae, and the teleomorph state of Fusarium graminearum}

In my graduate course at the Faculty of Pharmaceutical Sciences, Science University of Tokyo, I studied the geographic distribution of Gibberella zeae and the production of trichothecenes. G. zeae is the name of the teleomorph state of F. graminearum, and it produces perithecia, which are ovoid with a very rough tuberculate wall and are dark purple or black. The perithecia of G. zeae are found on a wide range of gramineous hosts, especially on rice stubble and gramineous grass debris in crop fields in Japan ${ }^{3)}$. Before starting my study, the natural occurrence of trichothecenes in wheat and barley cultivated in Japan had been reported by several Japanese researchers ${ }^{12,13)}$. The data suggested that the presence of DON and NIV may show geographical differences, possibly associated with the distribution of toxigenic Fusarium species ${ }^{12}$. Based on these previous studies, I collected the perithecia of G. zeae in 3 different regions under the direction of Dr. Masakatsu Ichinoe, who worked for the National Institute of Hygienic Sciences at that time.

By using single spore isolation, a single ascospore was randomly chosen from a mass of ascospores discharged from a mature perithecium. Seven ascospores per perithecium were obtained from the samples harvested. Among them, 113 isolates of G. zeae were tested for the production of trichothecenes. As a result, all isolates of G. zeae produced trichothecenes, and they were divided into two groups: DON-producing isolates and NIV-producing ones. As each DON and NIV is an independent end-product in the trichothecene biosynthetic pathway (Fig. 1), I proposed to introduce the concept of 'chemotype' for the two groups of G. zeae, referring to the nomenclature rule for fungi. Therefore, I used 'G. zeae DON-chemotype' and 'G. zeae 


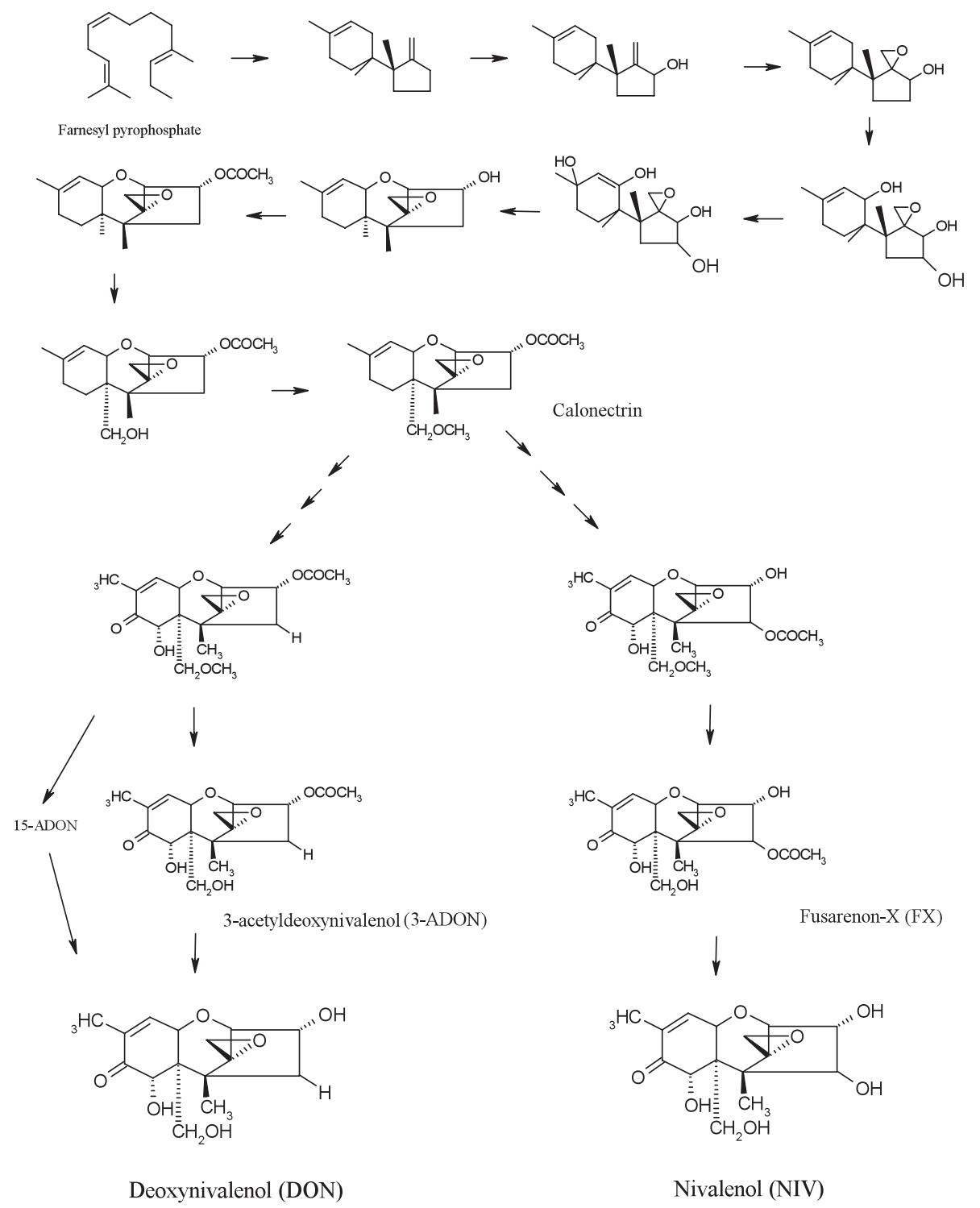

Fig. 1 Nivalenol and deoxynivalenol biosynthetic pathways

NIV-chemotype' for DON-producing G. zeae and NIV-producing G. zeae, respectively ${ }^{14)}$ (Fig. 2). The name of the teleomorph state is used prior to that of the anamorph stage according to the nomenclature rule. However, in 1991, Miller and co-workers ${ }^{15)}$ proposed enlarging the use of the 'chemotype' to three Fusarium species; F. graminearum, F. culmorum, and F. crookwellense belonging to the section Discolor of the genus Fusarium. Now, the broad use of 'chemotype' for the three Fusarium species has been accepted worldwide, and the DON or NIV chemotype are still used for the DON- or NIV-producing Fusarium species, respectively.

As described above, G. zeae was characterized by two different chemotypes. However, one question remained to be solved. Which chemotype does each of the eight ascospores in a single ascus show? The 


\section{G. zeae DON-chemotype}

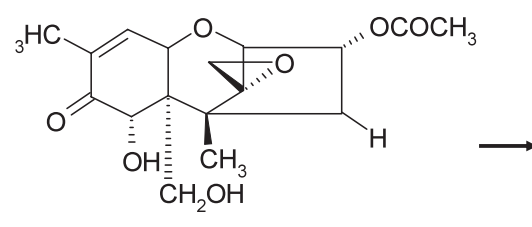

3-acetyldeoxynivalenol

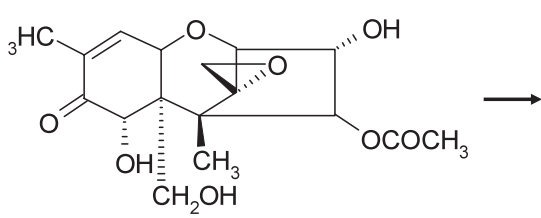

Fusarenon-X

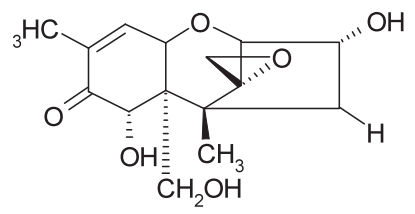

Deoxynivalenol

G. zeae NIV-chemotype

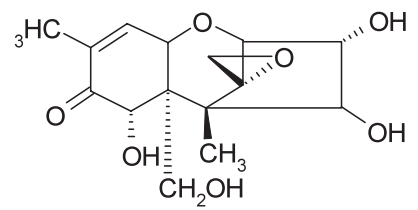

Nivalenol

Fig. 2 Two chemotypes of Gibberella zeae

question arose because random isolation of ascospores discharged from a perithecium was used to determine the chemotypes of G. zeae in a previous study ${ }^{14)}$. To answer this question, I separated each of eight ascospores from a single ascus by dissection. Then, each ascospore was examined for the production of trichothecenes. As shown in Table 1, each of eight ascospores was characterized with the same chemotype ${ }^{16)}$.

In a previous study ${ }^{16)}$, some ascospores from Miyagi Prefecture produced both DON and NIV, but their toxin levels were not equal. This suggested that crossing of G. zeae with two different chemotypes may occur in the field. Furthermore, G. zeae from Hirosaki in Aomori Prefecture produced only DON, but its precursors were two different acetyl derivatives, 3-ADON and 15-ADON. As shown in Table 1, each of the TK-1 and TH-4 isolates produced different types of acetyl derivatives; 3-ADON, 15-ADON, or both. However, all of these isolates produced only 15 -ADON when cultured at $25^{\circ} \mathrm{C}$ for 14 days followed by culture at $4{ }^{\circ} \mathrm{C}$ for 14 days (Table 2). The reason for the change to produce only 15-ADON was unclear at that time. Currently, the genetic basis for the difference in 3-ADON and 15-ADON has been identified ${ }^{17)}$, and further studies may solve the mystery of 15-ADON only production by low temperature treatment.

In 1982 during my graduate course, I studied the isolation and identification of Penicillium species obtained from several Indian rice grains under the guidance of Dr. Hiroshi Tsunoda. He was a famous scientist in Japanese mycotoxin research because he found for the first time NIV-producing Fusarium species from rice straws in the Kyushu region. While working with him, I heard his hypothesis on Akakabi-byo disease occurring in the crop fields of Japan. His theory was that spores of toxigenic Fusarium species were brought to Japan from China by seasonal a phenomenon known as “Kosa” in Japanese.

Actually, wind dispersion of Fusarium moniliforme conidia as far as $400 \mathrm{~km}$ has been reported in the United States $^{1)}$. However, I did not understand his explanation at that time. Later, I recalled his 'Kosa' hypothesis when I found some perithecia of G. zeae formed on the debris of a graminaceous grass near the top of a mountain in the Kyushu region. I tried taking spores of the Fusarium species on a flight, but I did not get the chance to clarify his hypothesis. Now, genetic approaches are a practical and useful tool for clarifying the geographical differences in toxigenic Fusarium strains derived from Japan or China. I hope that young 
Table 1. Production of 8-ketotrichothecenes by Gibberella zeae strains

\begin{tabular}{|c|c|c|c|c|c|c|c|c|c|}
\hline \multirow{2}{*}{$\begin{array}{l}\text { Group and } \\
\text { strain }\end{array}$} & \multirow{2}{*}{$\begin{array}{l}\text { 8-keto- } \\
\text { trichothecene }\end{array}$} & \multicolumn{8}{|c|}{ Production $(\mu \mathrm{g} / \mathrm{g})$ of 8 -ketotrichothecene by individual ascospores from an ascus } \\
\hline & & 1 & 2 & 3 & 4 & 5 & 6 & 7 & 8 \\
\hline \multicolumn{10}{|c|}{ DON group } \\
\hline \multirow[t]{5}{*}{ TK-1 } & NIV & ND & ND & ND & ND & ND & ND & ND & ND \\
\hline & 4-AcNIV & ND & ND & ND & ND & ND & ND & ND & ND \\
\hline & DON & 53.83 & 28.59 & 34.81 & 43.37 & 36.70 & 33.07 & 29.88 & 24.55 \\
\hline & 3-AcDON & 3.54 & 1.57 & 2.41 & 2.00 & 2.94 & 2.34 & 1.46 & 1.53 \\
\hline & 15-AcDON & ND & 1.13 & ND & ND & ND & 2.72 & ND & ND \\
\hline \multirow[t]{5}{*}{ TK-2 } & NIV & ND & ND & ND & ND & ND & ND & ND & ND \\
\hline & 4-AcNIV & ND & ND & ND & ND & ND & ND & ND & ND \\
\hline & DON & 3.69 & 4.06 & 3.08 & 5.17 & 4.04 & 2.10 & 3.31 & 2.65 \\
\hline & 3-AcDON & ND & ND & ND & ND & ND & ND & ND & ND \\
\hline & 15-AcDON & 1.75 & 1.37 & 1.57 & 1.76 & 1.27 & 1.03 & 1.49 & 0.69 \\
\hline \multirow[t]{5}{*}{ TH-4 } & NIV & ND & ND & ND & ND & ND & ND & ND & ND \\
\hline & 4-AcNIV & ND & ND & ND & ND & ND & ND & ND & ND \\
\hline & DON & 22.36 & 26.43 & 18.73 & 17.98 & 48.27 & 12.20 & 32.98 & 19.38 \\
\hline & 3-AcDON & ND & 1.69 & 1.80 & ND & 2.16 & ND & 2.07 & 1.86 \\
\hline & 15-AcDON & 4.82 & 1.07 & 2.91 & 9.84 & ND & 4.18 & 1.25 & 2.12 \\
\hline \multirow[t]{5}{*}{ TH-5 } & NIV & ND & ND & ND & ND & ND & ND & ND & ND \\
\hline & 4-AcNIV & ND & ND & ND & ND & ND & ND & ND & ND \\
\hline & DON & 186.52 & 203.64 & 76.66 & 160.52 & 272.18 & 127.46 & 366.97 & 146.90 \\
\hline & 3-AcDON & ND & ND & ND & ND & ND & ND & ND & ND \\
\hline & 15-AcDON & 11.84 & 12.66 & 5.23 & 8.96 & 26.68 & 11.30 & 64.17 & 9.45 \\
\hline \multicolumn{10}{|l|}{ NIV group } \\
\hline \multirow[t]{5}{*}{ TY-1 } & NIV & 15.52 & 4.77 & 102.43 & 13.06 & 11.54 & 6.41 & 12.86 & 0.97 \\
\hline & 4-AcNIV & 5.78 & 2.13 & 15.70 & 5.27 & 5.43 & 2.41 & 5.56 & ND \\
\hline & DON & 0.32 & 0.09 & 0.74 & 0.45 & 0.21 & 0.09 & 0.43 & 0.01 \\
\hline & 3-AcDON & ND & ND & ND & ND & ND & ND & ND & ND \\
\hline & 15-AcDON & ND & ND & ND & ND & ND & ND & ND & ND \\
\hline \multirow[t]{5}{*}{ MM-1 } & NIV & 0.75 & 0.66 & 0.75 & 0.24 & 0.18 & 0.06 & 0.87 & 0.60 \\
\hline & 4-AcNIV & 0.11 & 0.10 & 0.23 & 0.05 & 0.03 & 0.04 & 0.05 & 0.26 \\
\hline & DON & 0.02 & 0.01 & ND & ND & ND & ND & ND & ND \\
\hline & 3-AcDON & ND & ND & ND & ND & ND & ND & ND & ND \\
\hline & 15-AcDON & ND & ND & ND & ND & ND & ND & ND & ND \\
\hline \multirow[t]{5}{*}{ SC-1 } & NIV & 0.57 & 0.20 & 0.69 & 0.69 & 0.34 & 1.53 & 0.66 & 0.62 \\
\hline & 4-AcNIV & 0.16 & 0.01 & 0.11 & 0.10 & 0.05 & 0.30 & 0.25 & 0.04 \\
\hline & DON & ND & ND & 0.02 & ND & 0.01 & ND & ND & ND \\
\hline & 3-AcDON & ND & ND & ND & ND & ND & ND & ND & ND \\
\hline & 15-AcDON & ND & ND & ND & ND & ND & ND & ND & ND \\
\hline
\end{tabular}

scientists will prove Tsunoda's hypothesis; toxigenic F. graminearum are blown by winds to Japan together with Chinese soil ('Kosa'). 
Table 2. Production of 8-ketotrichothecenes with TK-1 and TH-4 strains after incubation at $25{ }^{\circ} \mathrm{C}$ for 14 days followed by $4{ }^{\circ} \mathrm{C}$ for 14 days

\begin{tabular}{llllllllll}
\hline \multirow{2}{*}{$\begin{array}{l}\text { Group and } \\
\text { strain }\end{array}$} & $\begin{array}{l}\text { 8-keto- } \\
\text { trichothecene }\end{array}$ & \multicolumn{7}{c}{ Production $(\mu \mathrm{g} / \mathrm{g})$ of 8 -ketotrichothecene by individual ascospores from an ascus } \\
\hline \multirow{2}{*}{ TK-1 } & NIV & ND & ND & ND & ND & ND & ND & ND & ND \\
& 4-AcNIV & ND & ND & ND & ND & ND & ND & ND & ND \\
& DON & 27.79 & 26.90 & 40.75 & 42.86 & 10.77 & 38.31 & 12.57 & 30.82 \\
& 3-AcDON & ND & ND & ND & ND & ND & ND & ND & ND \\
& 15-AcDON & 9.37 & 2.76 & 5.35 & 4.06 & 3.72 & 5.92 & 9.27 & 5.44 \\
TH-4 & NIV & ND & ND & ND & ND & ND & ND & ND & ND \\
& 4-AcNIV & ND & ND & ND & ND & ND & ND & ND & ND \\
& DON & 13.16 & 13.68 & 7.40 & 19.95 & 10.62 & 23.45 & 21.51 & 9.50 \\
& 3-AcDON & ND & ND & ND & ND & ND & ND & ND & ND \\
& 15-AcDON & 7.82 & 7.36 & 2.98 & 4.87 & 5.89 & 4.85 & 3.20 & 5.44 \\
\hline
\end{tabular}

\section{Natural occurrence of nivalenol in wheat and barley in Hokkaido}

The contamination of wheat and barley with DON and/or NIV has been observed frequently in Japan. Geographic differences in DON and NIV have been investigated in grain samples of wheat and barley harvested in several areas of Japan ${ }^{12,13}$. In Kyushu and Shikoku, DON is predominant over NIV, and NIV is predominant over DON from Chugoku to Tohoku. In the northernmost island, Hokkaido, DON is dominant in the wheat fields. In previous studies, the isolates of F. graminearum derived from wheat grains in Hokkaido were only DON producers ${ }^{18)}$. NIV contamination of wheat grains cultivated in Hokkaido was observed, but the fungi responsible for the natural occurrence of NIV were not identified ${ }^{19)}$. A mycological survey in Hokkaido demonstrated the presence of NIV-producing Fusarium poae in scabby wheat grains harvested in the Tokachi district ${ }^{18)}$.

Based on previous studies, I tried to find fresh toxigenic Fusarium species responsible for NIV production elsewhere in Hokkaido. On July 1991, I went to 19 wheat fields in eight locations in six districts of Hokkaido, Ebetsu, Shimidzu, Tokoro, Nayoro, Hippu, Furano, Kyogoku, and Hakodate, with the special assistances of agricultural agents who graduated from the Rakuno Gakuen University (lab students of Prof. Yukio Matsui). As a result of the mycological survey, F. poae and Fusarium crookwellense were found to be NIV producers responsible for the natural occurrence of wheat grains with NIV in Hokkaido ${ }^{20)}$. Especially, four isolates of domestic F. crookwellense were obtained for the first time from scabby wheat grains sampled in the Kyogoku district. Unfortunately, there are no reports on the natural distribution of F. crookwellense in other regions of Japan, except Hokkaido.

The isolates of F. crookwellense obtained from scabby wheat were tested for plant pathogenicity against wheat and barley plants with the kind help of Dr. Hatsuo Saitoh, who worked for the Tohoku National Agricultural Experiment Station at that time. All isolates tested were found to be virulent in wheat and barley plants within 15 days after fungal spore inoculation. Symptoms were mainly observed on the heads of test plants and were identified as scab disease. The pathogenic potential of $F$. crookwellense isolates was almost the same as that of a wheat pathogenic $F$. graminearum strain, which was used as a positive reference ${ }^{21)}$. In 
conclusion, it was demonstrated that the contamination of wheat and barley grains with NIV in Hokkaido was caused by the prevailing F. poae and F. crookwellense.

\section{Fumonisin production by domestic Fusarium species in Japan}

Fumonisins (FBs) have been implicated in a variety of animal toxicoses, including equine leukoencephalomalacis in horses, porcine pulmonary edema, and experimental liver cancer in rats ${ }^{1)}$. FBs were found as a metabolite of $F$. moniliforme, a major pathogen of maize and sorghum, in $1988^{22}$. However, no research was done on the natural occurrence of FBs in Japan for a long time. A mycological survey of an FBs-producing $F$. moniliforme was carried out in 1993. Maize stalk dribs formed on the perithecia of Gibberella species were sampled at a maize field in Kanuma in Tochigi Prefecture. It was identified as Gibberella fujikuroi, the teleomorph state of F. moniliforme. Four isolates of G. fujikuroi were obtained from ascospores by dissection. Surprisingly, among eight ascospores in an ascus, four were capable of growing on a PDA medium, but the remaining four were not recovered. This experimented three more times, but the results were the same. As $G$. fujikuroi is a heterothallic fungus, a killer factor may be introduced into the four cells in meiosis. The isolates obtained were tested for the production of FBs, and it appeared that domestic G. fujikuroi had good ability to produce FBs on corn grits at levels ranging from 15.7 to $251.7 \mu \mathrm{g} / \mathrm{g}$, but on rice grains FBs were detected at low concentrations ranging from 2.2 to $4.4 \mu \mathrm{g} / \mathrm{g}^{23)}$. This was the first report on the production of FBs by a domestic Fusarium species in Japan.

As described above, a mycological survey of FB-producing Fusarium was not conducted until relatively recently. One reason for the delay in the FBs research is that most Japanese mycotoxin researchers believed that $F$. moniliforme is a pathogen against rice plants and prevalent in rice fields, and therefore ignored the possible presence of FBs-producing Fusarium species in maize fields in Japan. Recently, F. moniliforme has been shown to be a complex species, including several different species belonging to the section Liseola. Subsequently, in the nomenclature of fungi, F. moniliforme was replaced by Fusarium verticillioides due to the priority of the latter name ${ }^{24)}$. As a result, the fungal pathogen for maize disease was found to be F. verticillioides that produces FBs, and its teleomorph is Gibberella moniliformis. The pathogen for rice disease is Fusarium fujikuroi, which causes the 'Bakanae' of rice disease in Japan, and produces a plant hormone, gibberellins. Its teleomorph is G. fujikuroi.

\section{Experimental model for murine pathogenicity of soil-borne Fusarium solani}

Recently, Fusarium species have emerged as opportunistic fungal pathogens in immunocompromised patients $^{25,26)}$. Fusarium solani, F. oxysporum, F. verticillioides (= F. moniliforme), and F. proliferatum cause hyalohyphomycosis ${ }^{1,27)}$ (This term refers to local and systemic infections caused by molds with hyaline and septate hyphae.). In addition, Fusarium species are resistant to several chemotherapeutic agents ${ }^{26,28)}$. Among the Fusarium species, F. solani is the most frequent cause of human infection. In Japan, several cases of nail or corneal infections with $F$. solani or $F$. oxysporum have been reported ${ }^{29)}$, but disseminated infection with Fusarium species is rare ${ }^{30,31)}$. However, a number of patients have recently been diagnosed with deep-seated $F$. solani infection.

Japanese scientists reported that soil-borne strains of F. solani produce cyclosporins A (CsA) and C 
$(\mathrm{CsC})^{32)}$, but no-one has examined CsA production by clinical isolates of F. solani. Therefore, I tried to determine whether clinical strains of $F$. solani possess the potential to produce CsA. It appeared that all tested strains derived from clinical sources produced $\mathrm{CsA}^{33}$. In this trial, I designed a simple analytical method for CsA production of tested strains. As shown in Fig. 3, fungal strains were cultured on YES agar plates at $28^{\circ} \mathrm{C}$ for 7 days. Four agar plugs from each plate-culture were cut out of the culture equidistant on the circumference of a $10 \mathrm{~mm}$ radius circle from the centre of a Petri dish by using a $7 \mathrm{~mm}$ (i.d.) sterile glass tube. Plugs were picked up with a sterile toothpick, transferred into a tared $20 \mathrm{ml}$ vial containing $5 \mathrm{ml}$ of methanol, and then re-weighted to calculate the weight of the agar plugs. After standing for 3 days at room temperature, a $1.25 \mathrm{ml}$ portion of the solution was transferred to a vial, and then evaporated to dryness under $\mathrm{N}_{2}$. These extracts were analyzed with HPLC equipment for CsA after simple purification ${ }^{33)}$ (Fig. 4).

CsA and CsC are cyclic undecapeptides with strong immunosuppressive activity; in mammals, they are also nephrotoxic. The immunosuppressive effect is mediated by inhibiting signal transduction, blocking both the transcription of lymphokine genes in T-lymphocytes and also the degranulation of granulocytes ${ }^{34)}$. However, there is no information on the relationship between cyclosporin production and the pathogenicity of F. solani in experimental or clinical hyalohyphomycosis or in plant pathology.

A previous report concerning a murine model for $F$. solani infection ${ }^{35)}$ demonstrated that an inoculum size of greater than $1 \times 10^{6}$ colony-forming units (CFU)/mouse was required to cause mortality in CF1 mice. Disseminated infection occurred in mice immunocompromised by an injection of cyclophosphamide. Other studies on experimental Fusarium infections have also been reported ${ }^{36-39)}$. These experiments were carried out

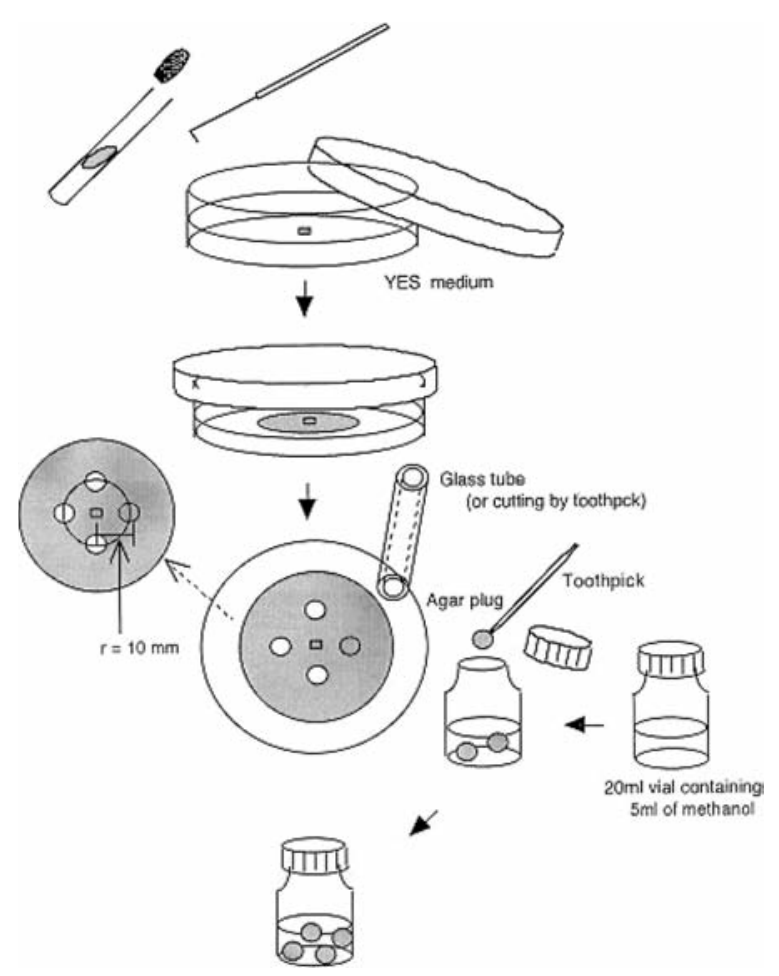

Fig. 3 Isolation of fungal metabolites 


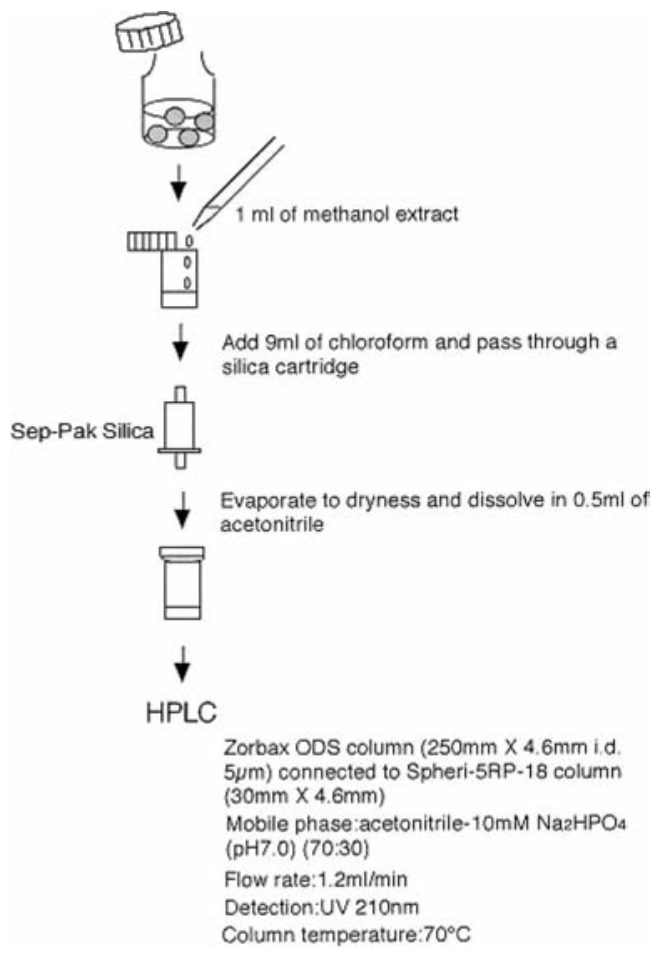

Fig. 4 Purification and HPLC analysis of cyclosporin A

with pathogenic strains of $F$. solani derived from clinical sources, but not with $F$. solani of environmental origin.

In view of the worldwide distribution of $F$. solani as a soil fungus, as well as of the capacity of this fungus to cause human infection, an experimental model to study the toxigenicity and pathogenic potential of soil-borne $F$. solani would contribute significantly to an understanding of opportunistic Fusarium infection. Two representative strains of $F$. solani were isolated from soils sampled from a crop field located at Hirosaki (Aomori Pref.) and Isahaya (Nagasaki Pref.) in northern and western regions of Japan, respectively. The $F$. solani strains were characterized by the ability to produce CsA and CsC, and were examined for their pathogenic potential in severe combined immunodeficiency (SCID) and BALB/c mice ${ }^{40)}$.

As shown in Table 3, the murine experimental trials demonstrated that no mortality was observed after single dose infection with 0.3-1.6 × 10 $0^{7} \mathrm{CFU} /$ mouse in SCID and BALB/c mice. However, 28.6 to $85.7 \%$ survival was observed over a 25 -day period, depending on the $F$. solani strain and the inbred mouse line used, when mice were infected with 0.8-1.5 × $10^{6} \mathrm{CFU} /$ mouse and two days later with 1.2-1.9 $\times 10^{6} \mathrm{CFU} / \mathrm{mouse}$. Death was preceded by renal insufficiency in both kidneys. Interestingly, i.v. injection with heat-killed conidia followed two days later by injecting viable conidia resulted in renal infection in both breeds of mice. $F$. solani isolated from infected organs was more virulent than the original isolate, and 37.5\% of BALB/c and 57.1\% of SCID mice died after receiving a single dose $\mathrm{e}^{40}$.

In the murine model experiment, soil-borne $F$. solani strains tested had poor pathogenic potential for mice, but either two successive infective doses or a primary injection with heat-killed conidia followed by a 
Table 3. Survival in mice inoculated intravenously with two strains of soil-borne Fusarium solani

\begin{tabular}{|c|c|c|c|c|c|c|c|}
\hline Trial & Strain & $\begin{array}{l}\text { Inoculum dose } \\
\text { (CFU/mouse) }\end{array}$ & $\begin{array}{l}\text { Mouse } \\
\text { strain }\end{array}$ & $\begin{array}{l}\text { No. mice } \\
\text { tested }\end{array}$ & $\begin{array}{l}\text { Median } \\
\text { survival time }\end{array}$ & $\begin{array}{l}\text { \% survival on } \\
\text { day } 25\end{array}$ & \\
\hline \multirow[t]{4}{*}{1} & Hirosaki & $3 \times 10^{6}$ & $\mathrm{BALB} / \mathrm{c}$ & 14 & $>25$ & 100 & \\
\hline & & $3 \times 10^{6}$ & SCID & 14 & $>25$ & 100 & \\
\hline & Isahaya & $1.6 \times 10^{7}$ & $\mathrm{BALB} / \mathrm{c}$ & 14 & $>25$ & 100 & \\
\hline & & $1.6 \times 10^{7}$ & SCID & 14 & $>25$ & 100 & \\
\hline \multirow[t]{4}{*}{2} & Hirosaki & ${ }^{\mathrm{a}} 1.3 \times 10^{6}+1.9 \times 10^{6}$ & $\mathrm{BALB} / \mathrm{c}$ & 7 & $>25$ & 57.1 & $(\mathrm{p}<0.05)^{\mathrm{e}}$ \\
\hline & & ${ }^{\mathrm{a}} 1.3 \times 10^{6}+1.9 \times 10^{6}$ & SCID & 7 & 20 & 28.6 & $(\mathrm{p}<0.01)^{\mathrm{e}}$ \\
\hline & Isahaya & ${ }^{\mathrm{a}} 0.8 \times 10^{6}+1.2 \times 10^{6}$ & $\mathrm{BALB} / \mathrm{c}$ & 6 & $>25$ & 66.7 & \\
\hline & & ${ }^{\mathrm{a}} 0.8 \times 10^{6}+1.2 \times 10^{6}$ & SCID & 7 & $>25$ & 85.7 & \\
\hline \multirow[t]{2}{*}{3} & Hirosaki & ${ }^{\mathrm{b}} 1 \times 10^{7}($ conidia/mouse $)+2.5 \times 10^{6}$ & $\mathrm{BALB} / \mathrm{c}$ & 7 & $>25$ & 85.7 & \\
\hline & & ${ }^{\mathrm{b}} 1 \times 10^{7}($ conidia/mouse $)+2.5 \times 10^{6}$ & SCID & 7 & $>25$ & 57.1 & $(\mathrm{p}<0.05)^{\mathrm{e}}$ \\
\hline \multirow[t]{2}{*}{4} & Hirosaki-amp ${ }^{c}$ & $0.6 \times 10^{6}$ & BALB/c & 8 & $>25$ & 62.5 & $(\mathrm{p}<0.05)^{\mathrm{e}}$ \\
\hline & Isahaya-amp $^{\mathrm{d}}$ & $4.3 \times 10^{6}$ & SCID & 7 & 18 & 42.9 & $(\mathrm{p}<0.01)^{\mathrm{e}}$ \\
\hline
\end{tabular}

${ }^{\text {a }}$ Primary injection with viable conidia followed 2 days later with secondary i.v. injection of viable conidia

${ }^{\mathrm{b}}$ Primary injection with heat-killed conidia followed 2 days later with secondary i.v. injection of viable conidia

${ }^{\mathrm{c}}$ Hirosaki-amp: strain isolated from a mouse brain after primary passage

${ }^{\mathrm{d}}$ Isahaya-amp: strain isolated from a mouse kidney after primary passage

${ }^{\mathrm{e}}$ Difference in survival was analyzed as compared with the same fungal and murine strains in trial 1

single infective dose broke through host defenses in normal and immunoincompetent mice. Mouse passage increased the pathogenicity of two soil-derived F. solani strains. Unfortunately, it seemed that medical researchers did not pay any attention to this new finding. This may be due to the lack of additional data to explain why two successive conidial doses are capable of breaking through the murine host defense system. I believe that this experimental result indicates the fragility of the host defense against secondary fungal invasion, and it will contribute to finding ways to prevent fungal infection.

\section{Acknowledgements}

Since I was admitted as a graduate student to the laboratory of Prof. Yoshio Ueno, the Faculty of Pharmaceutical Sciences, the Science University of Tokyo, in 1980, I have been engaged in Fusarium research on mycotoxins and pathogenicity against plants and mice for more than 25 years. During my studies at the Science University of Tokyo, I received excellent collaboration and encouragement from agricultural, chemical, and mycological researchers. Especially, I am deeply grateful to Drs. Yoshio Ueno, Masakatsu Ichinoe, Toshitsugu Tanaka, Yukio Matui, Hatsuo Saitoh, Errol Reiss, Susumu Kumagai, Yoshiko Konishi, lab staff and my students at the Science University of Tokyo. Lastly, I sincerely express my thanks to Prof. Mikio Yamazaki, who worked at Chiba University, for his warmest hospitality when I was jobless.

\section{References}

1 ) Nelson, P.E., Dignani, M.C., Anaissie, E.J.: Taxonomy, biology, and clinical aspects of Fusarium species. Clinical Microbiological Review, 7, 479-504 (1994) 
2 ) Tsunoda, H.: “Proceeding of the first U.S-Japan conference on toxic micro-organisms” (ed. Herzberg, M.), pp. 143-162 (1970), UJNR Joint Panel on Micro-organisms and U.S. Department of the Interior, Washington, D.C.

3 ) Nishikado, Y.: Studies on the wheat scab, caused by Gibberella zeae (Schw.) Petch and its control (1). Nogaku Kenkyu 45, 59-86 (1957) (in Japanese; English summary in Ber. Ohara Institute Landwirtsch Forsch, Okayama University, 11, 141-165, (1959))

4 ) Ueno, Y.: “Mycotoxins in human and animal health” (eds. Rodricks, J., Hesseltine, C.W., Mehlman, M.A.), pp.189-207 (1977), Pathotox Publishers, Inc., Park Forest South, IIIinois

5 ) Kurata, H.: Current scope of mycotoxin research from the viewpoint of food mycology, (1978), Kodansha, Tokyo

6 ) Tatsuno, T., Saito, M., Enomoto, M., Tsunoda, H.: Nivalenol, a toxic principle of Fusarium nivale. Chemical Pharmaceutical Bulletin, 16, 2519-2520 (1968)

7 ) Aoko, T., O’Donnell K..: Fusarium kyushuense sp. nov. from Japan. Mycoscience, 39, 1-6 (1998)

8 ) Ueno, Y., Ueno, I., Tatsuno, T., Ohokubo, K., Tsunoda, H.: Fusarenon-X, a toxic principle of Fusarium nivale-culture filtrate. Experientia, 25, 1062 (1969)

9 ) Yoshizawa, T., Morooka, N.: Deoxynivalenol and its monoacetate, new mycotoxins from Fusarium roseum and mouldy barley. Agricultural and Biological Chemistry, 37, 2933-2934 (1973)

10) Vesonder, R.F., Ciegler, A., Jensen, A.H.: Isolation of the emetic principle from Fusarium-infected corn. Applied Microbiology, 26, 1008-1010 (1973)

11) Okada, G.: Unified nomenclature for anamorphic fungi or fungi with a pleomorphic life cycle adopted at the 18 the International Botanical Congress. Japanese Journal of Mycology, 52, 82-97 (2011) (in Japanese; English summary)

12) Yoshizawa, T., Matuura, Y., Tsuchiya, Y., Morooka, N., Kitani, K., Ichinoe, M., Kurata, H.: On the toxigenic fusaria invading barley and wheat in the southern Japan. Journal of Hygiene Society of Japan, 20, 21-25 (1979)

13) Ichinoe, M., Amano, R., Morooka, N., Yoshizawa, T., Suzuki, T., Kurisu, M.: Geographic difference of toxigenic fungi of Fusarium species. Proceeding of Japanese Association of Mycotoxicology, 11, 20-22 (1980) (in Japanese)

14) Ichinoe, M., Kurata, H., Sugiura, Y., Ueno, Y.: Chemotaxonomy of Gibberella zeae with special reference to production of trichothecenes and zearalenone. Applied and Environmental Microbiology, 46, 1364-1369 (1983)

15) Miller, J.D., Greenhalgh, R., Wang, Y.Z., Lu, M.: Trichothecene chemotypes of three Fusarium species. Mycologia, 83, 121-130 (1991)

16) Sugiura, Y., Watanabe, Y., Tanaka, T., Yamamoto, S., Ueno, Y.: Occurrence of Gibberella zeae strains that produce both nivalenol and deoxynivalenol. Applied and Environmental Microbiology, 56, 3047-3051 (1990)

17) Alexander, N.J., McCormick, S.P., Waalwijk, C., van der Lee, T., Proctor, R.H.: The genetic basis for 3 -ADON and 15 -ADON trichothecene chemotypes in Fusarium. Fungal Genetics and Biology, 48, 485-495 (2011)

18) Tanaka, T., Hasegawa, A., Yamamoto, S., Toyazaki, M., Masuda, Y., Sugiura, Y., Ueno, Y: Production of mycotoxins by Fusarium isolates from scabby wheat harvested in Hokkaido, Japan. Proceeding of 
Japanese Association of Mycotoxicology, 25, 31-33 (1987)

19) Tanaka, T., Hasegawa, A., Matsuki, Y., Matsui, Y., Lee, U-S., Ueno, Y.: Co-contamination of the Fusarium mycotoxins, nivalenol, deoxynivalenol, and zearalenone, in scabby wheat grains harvested in Hokkaido, Japan. Journal of Food Hygiene Society of Japan, 26, 519-522 (1985)

20) Sugiura, Y., Fukasaku, K., Tanaka, T., Matsui, Y., Ueno, Y.: Fusarium poae and Fusarium crookwellense, fungi responsible for the natural occurrence of nivalenol in Hokkaido. Applied and Environmental Microbiology, 59, 3334-3338 (1993)

21) Sugiura, Y., Saito, H., Tanaka, T., Ichinoe, M., Ueno, Y.: Fusarium crookwellense, a newly isolated fungus from wheat in Japan: Its mycotoxin production and pathogenicity to wheat and barley. Mycoscience, 35, 77-82 (1994)

22) Gelderblom, W.C.A., Jaskiewicz, K., Marasas, W.F.O., Thiel, P.G., Horak, R.M., Vieggaar, R., Kriek, N.P.: Fumonisins-novel mycotoxins with cancer-promoting activity produced by Fusarium moniliforme. Applied and Environmental Microbiology, 54, 1806-1818 (1988)

23) Ueno, Y., Aoyama, S., Sugiura, Y., Wang, D-S, Lee, U-S, Hirooka, EY, Hara, S., Karki, T., Chen, G., Yu, S-Z.: A limited survey of fumonisins in corn and corn-based products in Asian countries. Mycotoxin Research, 9, 27-34 (1993)

24) Seifert, K.A., Aoki, T., Baayen, R.P., Brayford, D., Burgess, L.W., Chulze, S., Gams, W., Geiser, D., de Gruyter, D.J., Leslie, J.F., Logrieco, A., Marasas, W.F.O., Nirenberg, H.I., O’Donnell, K., Rheeder, J.P., Samuels, G.J., Summerell, B.A., Thrane, U., Waalwijk, C.: The name Fusarium moniliforme should no longer be used. Mycological Research, 107, 643-644 (2003)

25) Guarro J., Gené J.: Opportunistic fusarial infections in humans. European Jouranal of Clinical Microbiology and Infectious Disseases, 14, 741-754 (1995)

26) Schell, A.W.: New aspects of emerging fungal pathogens. a multifaceted challenge. Contemporary Issues in Clinical Microbiology 15, 365-387 (1995)

27) Rabodonirina, M., Piens, M.A., Monier, M.F., Guého, E., Fière, D., Mojion, M.: Fusarium infections in immunocompromised patients: case reports and literature review. European Jouranal of Clinical Microbiology and Infectious Disseases, 13, 152-161 (1994)

28) Martina, P., Gastaldi, R., Raccah, R., Girmenia, C.: Clinical patterns of Fusarium infections in immunocompromised patients. Journal of Infection, 28, suppl I, 7-15 (1994)

29) Ichinoe, M.: Pathogenicity and toxigenicity of the members of genus Fusarium. Nishinihon Journal of Dermatology, 40, 613-619 (1978) (in Japanese)

30) Matsuda, T., Matsumoto, T.: Disseminated hyalohyphomycosis in a leukemic patient. Archives of Dermatology, 122, 1171-1175 (1986)

31) Saito, T., Imaizumi, M., Kudo, K., et al.: Disseminated Fusarium infection identified by the immunohistochemical staining in a patient with a refractory leukemia. Tohoku Journal of Experimental Medicine, 187, $71-77$ (1999)

32) Sawai, K., Okuno, T., Terada, Y.,Harada, Y., Sawamura, K., Sawaki, H., Takao, S.: Isolation and properties of two antifungal substances from Fusarium solani. Agricultural and Biological Chemistry, 45, 1223-1228 (1981)

33) Sugiura, Y., Barr, J.R., Barr, D.B., Brock, J.W., Elie, C.M., Ueno, Y., Patterson, Jr., D.G., Potter, M.E., Reiss, E.: Physiological characteristics and mycotoxins of human clinical isolates of Fusarium species. 
Mycological Research, 103, 1462-1468 (1999)

34) Balakrishnan, K., Pandey, A.: The panorama of cyclosporin research. Journal of Basic Microbiology, 36, 121-147 (1996)

35) Legrand, C., Anaissie, E., Hashem, R., Nelson, P., Bodey, G.P., Ro, J.: Experimental fusarial hyphomycosis in a murine model. Journal of Infectious Disease, 164, 944-948 (1991)

36) Anaissie, E.J., Hachem, R., Legrand, C., Legenne, P., Nelson, P., Bodey, G.P.: Lack of activity of amphotericin B in systemic murine fusarial infection. Journal of Infectious Disease, 165, 1155-1157 (1992)

37) Guarro, J., Pujol, I., Mayayo, E.: In vitro and in vivo experimental activities of antifungal agents against Fusarium solani. Antimicrobial Agents and Chemotherapy, 43, 1256-1257 (1999)

38) Mayayo, E., Guarro, J., Pujol, I.: Endogenous endophthalmitis by Fusarium solani: an animal experimental model. Medical Mycology, 36, 249-253 (1998)

39) Mayayo, E., Pujol, I., Guarro, J.: Experimental pathogenicity of four opportunist Fusarium species in a murine model. Journal of Medical Microbiology, 48, 363-366 (1999)

40) Sugiura, Y., Sugita-Konishi, Y., Kumagai, S., Reiss, E.: Experimental murine hyalohyphomycosis with soil-derived isolates of Fusarium solani. Medical Mycology, 41, 241-247 (2003) 